\title{
Incidence and outcome of inappropriate in-hospital empiric antibiotics for severe infection: a systematic review and meta-analysis
}

\author{
Kristel Marquet ${ }^{1,2^{*}}$, An Liesenborgs ${ }^{2}$, Jochen Bergs ${ }^{3}$, Arthur Vleugels ${ }^{1,4}$ and Neree Claes ${ }^{1,5}$
}

\begin{abstract}
Introduction: The aims of this study were to explore the incidence of in-hospital inappropriate empiric antibiotic use in patients with severe infection and to identify its relationship with patient outcomes.

Methods: Medline (from 2004 to 2014) was systematically searched by using predefined inclusion criteria. Reference lists of retrieved articles were screened for additional relevant studies. The systematic review included original articles reporting a quantitative measure of the association between the use of (in)appropriate empiric antibiotics in patients with severe in-hospital infections and their outcomes. A meta-analysis, using a random-effects model, was conducted to quantify the effect on mortality by using risk ratios.

Results: In total, 27 individual articles fulfilled the inclusion criteria. The percentage of inappropriate empiric antibiotic use ranged from 14.1\% to 78.9\% (Q1-Q3: 28.1\% to 57.8\%); 13 of 27 studies (48.1\%) described an incidence of $50 \%$ or more. A meta-analysis for 30-day mortality and in-hospital mortality showed risk ratios of 0.71 ( $95 \%$ confidence interval 0.62 to 0.82 ) and 0.67 (95\% confidence interval 0.56 to 0.80), respectively. Studies with outcome parameter 28 -day and 60-day mortality reported significantly $(P \leq 0.02)$ higher mortality rates in patients receiving inappropriate antibiotics. Two studies assessed the total costs, which were significantly higher in both studies $(P \leq 0.01)$.
\end{abstract}

Conclusions: This systematic review with meta-analysis provides evidence that inappropriate use of empiric antibiotics increases 30-day and in-hospital mortality in patients with a severe infection.

\section{Introduction}

Infections are among the top three leading causes of death worldwide [1]. Septicaemia and pneumonia combined are the sixth most common causes of death in the United States [2]. Bloodstream infections (BSIs) are associated with substantial morbidity, mortality, and health-care costs [3]. Sepsis is one of the leading causes of death in the critically ill, with a mortality rate of $28 \%$ to $55 \%$ [4]. Antibiotics are the mainstay of treatment for these serious infections [5]. Antibiotic treatment for moderate to severe infections has to start early and, in the absence of evidence on the causative pathogen or its sensitivity to antibiotics, is often guided by empirical evidence [6].

\footnotetext{
* Correspondence: kristel.marquet@uhasselt.be

'Hasselt University, Faculty of Medicine and Life Sciences, Agoralaan, Building D, Room C53, Diepenbeek BE3590, Belgium

2Jessa Hospital, Stadsomvaart 11, Hasselt BE3500, Belgium

Full list of author information is available at the end of the article
}

Estimates of the potential benefit of appropriate empirical antibiotic treatment (AAT) vary widely [7-11]. Studies on the effect of inappropriate empiric antibiotic therapy (IAAT) on patient outcomes have yielded variable results $[6,12]$. Nevertheless, it is common wisdom that IAAT may lead to progressive deterioration and the development of complications or mortality [13-18].

Given the high incidence of infections and the not well-established relationship between empiric (I)AAT and clinical outcome [19-22], it is necessary to synthese the best available evidence. This systematic review with meta-analysis was conducted to synthesize the best available evidence regarding (1) the definition, (2) the incidence, and (3) the outcome of empiric IAAT.

\section{Methods}

Data sources and search strategy

Quantitative studies on the association between the use of empiric (I)AAT in patients with a severe infection and 
their outcome in public or private general hospital settings were searched in Medline. Studies published in the last 10 years (20 August 2004 to 20 August 2014) were selected as critical illness management changes continuously and earlier and earlier studies may be less relevant for current practice. The following Medical Subject Headings $(\mathrm{MeSH})$ search terms and free-text terms were used either individually or in combination: 'antibiotic', 'infection', 'appropriate', 'inappropriate', 'adequate', 'inadequate', 'outcome', 'mortality', 'survival rate', 'cost', and 'length of stay'. Only studies published in English, Dutch, German, or French were included. Reference lists of retrieved articles were hand-searched for additional relevant studies. A detailed description of the search strategy is included in the Additional file 1: digital content.

\section{Eligibility criteria Study design}

Potentially included study designs included randomized controlled trials (RCTs), non-randomized controlled trials, controlled before-after studies, interrupted time series, and repeated measures studies. Only studies reporting a quantitative evaluation regarding the association between the use of AAT or IAAT in patients with a severe infection and their outcomes within the hospital setting were included. The studies use (I)AAT as the independent variable and outcome-measured as mortality, hospital length of stay (LOS), and costs-as the dependent variable. Studies that recruited less than 75 patients were excluded because the research team assumes that these studies bear the risk to be underpowered.

\section{Patients}

The included patients were adults (at least 18 years old) with a severe infection. For this review, pneumonia, BSI or bacteraemia, sepsis, severe sepsis, or septic shock were considered severe infections. Studies specifically focused on meningitis, endocarditis or infections in burn and transplant patients were excluded as the literature showed that treatment effects are expected to largely deviate from any common effect.

\section{Intervention}

The intervention of interest concerned empiric AAT versus IAAT. Empiric antibiotic therapy is defined as all nondefinitive therapy and refers to antibiotics given prior to the result of the final culture and the antibiotic sensitivity tests [23]. Studies that did not specify the used definition of AAT or IAAT were excluded. Studies comparing two or more types of antibiotics were excluded.

\section{Outcome}

Outcomes were assessed in terms of mortality, hospital LOS, and costs.

\section{Study appraisal}

Two reviewers (KM and AL) independently performed the initial scan of titles and abstracts of all retrieved citations by using standardized screening forms. Both reviewers documented the reasons for exclusion. Full-text copies of all potentially relevant studies were obtained and further checked for inclusion. Any discrepancies between reviewers were resolved by discussion. Continuing disagreements were settled by a third reviewer (NC or AV). Additional sources that had been cross-referenced from the Medline search results were included if they met the criteria above. The quality of the articles was evaluated by using the Downs and Black quality assessment method, which is a list of 27 criteria to evaluate both randomized and non-randomized trials [24]. This scale assesses study reporting, external validity, internal validity, and power of non-randomized studies and has been ranked in the top six quality assessment scales suitable for use in systematic reviews $[25,26]$. As had been done in other reviews using the Downs and Black scale [27-29], the tool was modified slightly for use in this particular review. Specifically, the scoring for question 27 dealing with statistical power was simplified to a choice of awarding either 1 point or 0 points, depending on whether there was sufficient power to detect a clinically important effect. The criterion was that to detect a $10 \%$ difference, assuming power of 0.90 and alpha of 0.05 . The Downs and Black scores were grouped into the following 4 quality levels: excellent (26 to 28 ), good (20 to 25 ), fair (15 to 19) and poor (less than 14) [29]. Only articles with a quality level of good or excellent were retained.

\section{Data extraction}

Data extraction was completed independently by two reviewers (KM and $\mathrm{AL}$ ), who used a standardized data collection form. The following data were extracted and reported: (1) data on study setting and patient population as possible confounding factors, (2) definition and incidence of the (I)AAT, and (3) definition and measurement of outcome variables (in terms of mortality, hospital LOS, and costs among patients given AAT versus IAAT). In case of disagreement between the two reviewers, a third reviewer (NC or AV) extracted the data.

\section{Study characteristics}

For every included study, descriptive data on the study setting (that is, study design, geographic location of the study, baseline characteristics, study years, and sample size) and patient characteristics (that is, source of infection and severity scale) were collected.

\section{Definition and measuring incidence of (I)AAT}

We reviewed how empiric (I)AAT was defined and measured. We assessed which evidence-based elements, 
such as therapy dose, route, and timing, were evaluated. Empiric antibiotic therapy is defined as all non-definitive therapy and refers to antibiotics given prior to the result of the final culture and the antibiotic sensitivity tests [23].

\section{Measurement of the dependent variable}

The outcome was measured as mortality, LOS, and costs for patients given empirical (I)AAT. The time span of mortality assessment was also registered.

\section{Data analysis}

Data were analyzed by using $\mathrm{R}$ (a language and environment for statistical computing) [30]. All reported $P$ values were two-sided; $P<0.05$ was considered to indicate statistical significance. A random-effects meta-analysis using the DerSimonian-Laird estimator obtained risk ratios (RRs) and $95 \%$ confidence intervals (CIs) for mortality rate reductions [31]. Heterogeneity of the study results was assessed by using the Cochran $\mathrm{Q}$ test and the Higgins $\mathrm{I}^{2}$ test. The following thresholds were used to quantify heterogeneity: $P<0.10$ in Cochran's $Q$ test and $\mathrm{I}^{2} \leq 25 \%$ for low,
$25 \%<\mathrm{I}^{2}<50 \%$ for moderate, and $\mathrm{I}^{2} \geq 50 \%$ for high. Funnel plots assessed publication bias. Sensitivity analysis identified heterogeneous studies that influenced the metaanalysis. Meta-regression was used to examine the impact of study characteristics on study effect size and heterogeneity.

\section{Results}

\section{Results of the search}

The initial database search identified 1,097 unique citations. Review of the reference lists of included studies identified 11 additional studies. After critical assessment of these 1,108 publications, 32 individual trials [8,12,19,21,22,32-58] fulfilled the inclusion criteria and were considered for further analysis (Figure 1). After quality assessment of the individual studies, 27 studies $[8,12,19,21,22,33,34$, $36-48,50-52,54-57]$ were included in the systematic review.

\section{Study characteristics}

Characteristics of the 27 included studies are presented in Table 1. The studies were conducted in Asia $(\mathrm{n}=9) \quad[8,12,21,41,44,50-52,55]$, North America $(\mathrm{n}=8)$

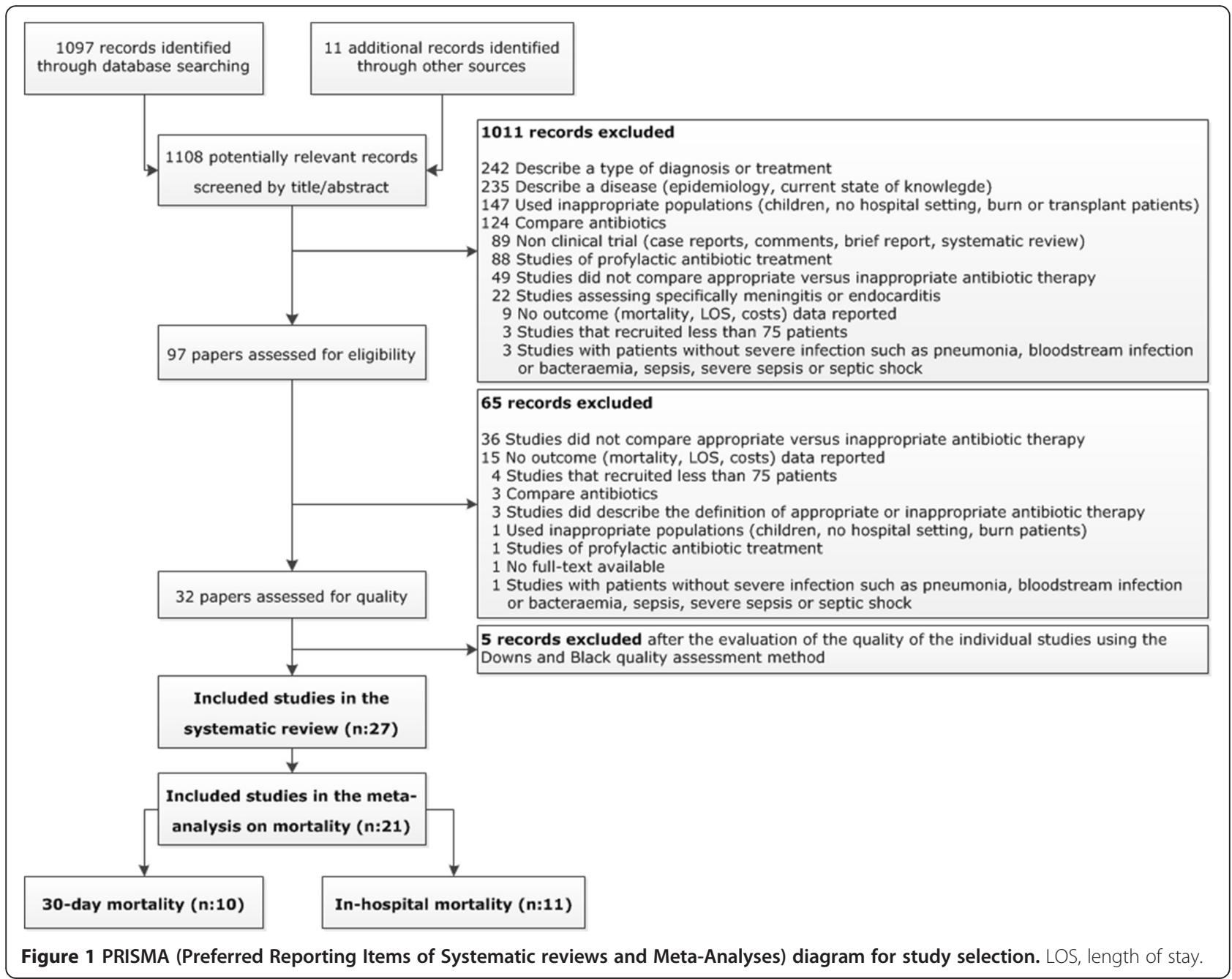


Table 1 Characteristics of 27 included studies in the systematic review

\begin{tabular}{|c|c|c|c|c|c|c|c|c|c|}
\hline \multirow[t]{2}{*}{ Reference } & \multirow[t]{2}{*}{ Study year(s) } & \multirow[t]{2}{*}{ Location } & \multirow[t]{2}{*}{ Design } & \multicolumn{2}{|l|}{ Center } & \multirow{2}{*}{$\begin{array}{l}\text { Number of } \\
\text { patients }\end{array}$} & \multirow[t]{2}{*}{ Outcome } & \multirow[t]{2}{*}{ Main type of infection } & \multirow{2}{*}{$\begin{array}{l}\text { Severity index scale and } \\
\text { significance difference }\end{array}$} \\
\hline & & & & Number & $\overline{\text { Type }}$ & & & & \\
\hline Kim et al. [21] ${ }^{\mathrm{a}}$ & $1998-2001$ & Korea & $\mathrm{R}$ & 1 & U & 127 & M & MRSA bacteremia & McCabe's classification, Jackson: NS \\
\hline Kang et al. [12] $]^{a}$ & 1998-2002 & Korea & $\mathrm{R}$ & 2 & $U, G$ & 286 & M & $\begin{array}{l}\text { Antibiotic-resistant } \\
\text { Gram-negative Bacilli BSI }\end{array}$ & APACHE II: NS \\
\hline Micek et al. [33] ${ }^{a}$ & 1997-2002 & USA & R & 1 & U & 305 & M & Pseudomonas aeruginosa BSI & SAPS ॥: NC \\
\hline Luna et al. [34] & $1999-2003$ & Argentina & $P$ & 6 & NM & 76 & M & Pneumonia (VAP) & APACHE II: NS \\
\hline Kim et al. [8] & 1998-2001 & South Korea & R & 1 & $U$ & 238 & M & $S A B$ & $\begin{array}{l}\text { McCabe's classification, } \\
\text { Jackson: NS }\end{array}$ \\
\hline Scarsi et al. [22] $]^{a}$ & $2001-2003$ & USA & $\mathrm{R}$ & 1 & $U$ & 884 & M & Gram-negative BSI & Charlson index: NS \\
\hline Marschall et al. [36] ${ }^{a}$ & $2006-2007$ & USA & $P$ & 1 & T & 250 & M LOS & Gram-negative bacteremia & $\begin{array}{l}\text { Charlson index, McCabe's } \\
\text { classification: NS }\end{array}$ \\
\hline Shorr et al. [37] $]^{a}$ & $2002-2004$ & USA & $\mathrm{R}$ & 1 & U & 291 & M LOSC & MRSA infection & NM \\
\hline Rodríguez-Baño et al. [38] $]^{a}$ & 2003 & Spain & $P$ & 59 & $U, G$ & 209 & M & Sepsis & Charlson index: NC \\
\hline Ammerlaan et al. [39] ${ }^{a}$ & 2007 & West European countries & $\mathrm{R}$ & 60 & $\mathrm{~T}, \mathrm{G}$ & 334 & M & $S A B$ & Modified Charlson index: NS \\
\hline Erbay et al. [19] $]^{a}$ & $2005-2008$ & Turkey & $\mathrm{R}$ & 1 & $U$ & 103 & M & Acinetobacter baumannii bacteremia & APACHE II: NC \\
\hline Kumar et al. [40] ${ }^{a}$ & $1996-2005$ & Canada, USA, Saudi Arabia & R & 22 & $U$ & 5,715 & M & Septic shock & APACHE II: NC \\
\hline Tseng et al. [41] ${ }^{a}$ & $2005-2007$ & Taiwan & $\mathrm{R}$ & 1 & T & 163 & M & Pneumonia & Charlson index: NC \\
\hline Micek et al. [42] ${ }^{a}$ & $2002-2007$ & USA & $\mathrm{R}$ & 1 & $U$ & 760 & M & Gram-negative sepsis & APACHE II, Charlson index: NS \\
\hline Paul et al. [43] ${ }^{\mathrm{a}}$ & 1999-2007 & Israel & R & 1 & NM & 510 & M & MRSA bacteremia & NM \\
\hline Joung et al. [44] $]^{a}$ & $2000-2006$ & Korea & $\mathrm{R}$ & 1 & $U$ & 116 & M & $\begin{array}{l}\text { Pneumonia (HAP) } \\
\text { Acinetobacter baumannii }\end{array}$ & APACHE II: NS \\
\hline Shorr et al. [45] & $2002-2007$ & USA & R & 1 & $U$ & 760 & LOS & Gram-negative sepsis & APACHE II, Charlson index: NS \\
\hline Suppli et al. [46] ${ }^{\mathrm{a}}$ & $2002-2005$ & Denmark & $R$ & 1 & T & 196 & M & Enterococcal BSI & $\begin{array}{l}\text { Charlson index: NS, except } \\
\text { score } 0(P=0.04)\end{array}$ \\
\hline Reisfeld et al. [47] ${ }^{\mathrm{a}}$ & $2005-2007$ & Israel & $\mathrm{R}$ & 1 & G & 378 & M & Gram-negative bacteremia & NM \\
\hline Wilke et al. [48] $]^{a}$ & 2007 & Germany & $\mathrm{R}$ & 5 & T & 221 & M LOS C & Pneumonia (VAP, HAP) & NM \\
\hline Lye et al. [50] ${ }^{a}$ & 2007-2009 & Singapore & R & 2 & G & 675 & M & Gram-negative bacteremia & APACHE $\|<0.001$; Charlson index: NS \\
\hline Tseng et al. [51] & $2007-2008$ & Taiwan & R & 1 & $U$ & 163 & M & Pneumonia (VAP) & APACHE II, Charlson index, SOFA: NC \\
\hline Chen et al. [52] & 2006-2011 & China & R & 1 & T & 118 & M & $S A B$ & APACHE II: NC \\
\hline Labelle et al. [54] ${ }^{a}$ & $2002-2007$ & USA & $\mathrm{R}$ & 1 & T & 436 & M & Septic shock & APACHE II, Charlson index: NC \\
\hline Chen et al. [55] & 2008-2009 & Taiwan & $P$ & 1 & $U$ & 937 & M, LOS & BSI & MEDS, Charlson index: NC \\
\hline Frakking et al. [56] ${ }^{\mathrm{a}}$ & $2008-2010$ & The Netherlands & R & 8 & $U$ & 232 & M & ESBL bacteremia & Pitt bacteremia score: NS \\
\hline Tumbarello et al. [57] ${ }^{a}$ & $2008-2010$ & Italy & R & 1 & $U$ & 110 & M & Pseudomonas aeruginosa pneumonia & SAPS II, SOFA: NS \\
\hline
\end{tabular}

${ }^{2}$ Twenty-one included studies in meta-analysis. APACHE II, Acute Physiology and Chronic Health Evaluation II; BSI, bloodstream infection; C, costs; ESBL, extended-spectrum $\beta$-lactamase; G, general hospital; HAP, hospital-acquired pneumonia; LOS: Length Of Stay; M, mortality; MEDS, Mortality in Emergency Department Sepsis; MRSA, Methicillin-resistant Staphylococcus Aureus; NC, no comparison; NM, not mentioned; NS, not significant; P, prospective; R, retrospective; SAB, Staphylococcus Aureus bacteraemia; SAPS II, Simplified Acute Physiology Score II; SOFA, Sequential Organ Failure Assessment; T, teaching hospital, U, university hospital; USA, United States of America; VAP, ventilator-associated pneumonia. 
$[22,33,34,36,37,42,45,54]$, Europe $(n=6)[19,38,46,48,56,57]$, and the Middle East $(\mathrm{n}=2)[43,47]$, and two studies were multinational $[39,40]$. Eight studies $(29.6 \%)$ were multicenter trials (range 2 to 60) [12,34,38-40,48,50,56]. Twenty studies (74.1\%) were conducted in university or teaching hospitals $[8,19,21,22,33,36,37,40-42,44-46,48,51$, 52,54-57], three studies (11.1\%) combined university and general hospitals $[12,38,39]$, two studies $(7.4 \%)$ were performed in general hospitals [47,50], and two studies (7.4\%) did not mention the nature of the site [34,43]. Twenty-three studies (85.2\%) reported on retrospective analysis $\quad[8,12,19,21,22,33,34,37,39-46,48,51,52,54,56,57]$. Included studies covered a total of 15,306 patients, with an average of 567 patients per study (range 76 to 5,715 ). The severe infection was BSI or bacteremia in 15 studies (55.5\%) [8,12,19,21,22,33,36,37,39,46,47,50,52,55,56], pneumonia in six studies $(22.2 \%),[34,41,44,48,51,57]$, and sepsis in three studies $[38,42,45]$; two studies described severe sepsis or septic shock $[40,54]$. Severity of illness was reported in 23 studies (85.2\%) using a variety of severity indexes, including the Acute Physiology and Chronic Health Evaluation (APACHE) II [59], Charlson index [60], the Sequential Organ Failure Assessment (SOFA) [61], Simplified Acute Physiology Score (SAPS) II [62], Multiple Organ Dysfunction Scale (MODS) [63], Pitt Bacteremia score [64], and McCabe's classification [65]. A significant difference $(P=0.04)$ in illness severity between the two groups was found in two studies [46,50]. However, nine studies [19,33,38,40,50-52,54,55] did not compare the severity of illness between patients with IAAT versus AAT.

\section{Data on definition and measurement of (I)AAT}

Data on the definition and the incidence of (I)AAT were presented in Table 2. A spectrum of definitions exists in the literature concerned. Fifteen (55.6\%) studies included a definition of AAT, four studies (14.8\%) mentioned a definition of IAAT, and eight studies (29.6\%) defined both. Thirty-two (94.1\%) of the 34 definitions mentioned the element 'matching with the in vitro susceptibility' or 'intermediate or full in vitro resistance'. Other frequently mentioned definitions items were the timing of administration $(n=24,70.6 \%)$, the correct dose $(n=8$, 23.5\%), and the correct indication for the antibiotics $(\mathrm{n}=6,17.6 \%)$.

The percentage of empiric IAAT showed an enormous range from $14.1 \%$ to $78.9 \%$ (median of $49,26 \%$, interquartile range $28.1 \%$ to $57.8 \%$ ). The magnitude of this range can be explained in part by the differences in the definitions, settings, diseases, and infectious agents. Because of this considerable heterogeneity, it may be misleading to quote an average value for the incidence. However, 13 (48.1\%) of these 27 studies described an incidence of IAAT of $50 \%$ or more.

\section{Measurement of the dependent variable}

Outcome was measured as mortality, LOS, and costs. A meta-analysis was conducted to quantify the effect of appropriateness in empiric antibiotics on mortality. The number of studies that assess the total LOS $[48,55]$, LOS after infection onset $[36,45]$, and the costs $[37,48]$ were very small. Therefore, these results are presented in a descriptive manner only.

\section{Mortality}

In total, 26 studies $[8,12,19,21,22,33,34,36-44,46-48,50$, 51,54-57] reported mortality as an outcome variable in patients with severe infection treated with (I)AAT. However, the time span of mortality assessment varied from $28[34,55]$ to $30[12,19,21,38,39,43,44,46,47,56]$ to 60 [51] days to 12 weeks [8]. Eleven studies [22,33,36,37, 40-42,48,50,54,57] assessed in-hospital mortality. Given methodological considerations, meta-analysis on the effect of AAT on 30-day mortality $(\mathrm{n}=10)$ and in-hospital mortality $(\mathrm{n}=11)$ was conducted separately (Table 3$)$. Five $[12,19,43,44,46]$ of the 10 studies reporting on 30-day mortality showed a significant lower mortality for patients treated with AAT compared with those treated with IAAT. Meta-analysis for 30-day mortality revealed an RR of 0.71 (95\% CI 0.62 to $0.82 ; P<0.0001$ ) in favor of AAT, without significant heterogeneity: Cochran's $\mathrm{Q}=11.37,9$ degrees of freedom (d.f.), $P=0.252$; $\mathrm{I}^{2}=20.8(0 \%$ to $61 \%)$ (Figure 2). Of the 11 trials $[22,33,36,37,40-42,48,50,54,57]$ included in the metaanalysis on in-hospital mortality, eight trials [33,40-42, $48,50,54,57$ ] yielded significant lower mortality ratios in patients receiving AAT. Meta-analysis for in-hospital mortality revealed that an RR of 0.67 (95\% CI 0.56 to $0.80 ; P<0.0001)$ in favor of AAT. However, there was significant heterogeneity: Cochran's $\mathrm{Q}=74.45,10$ d.f., $P<0.0001 ; \mathrm{I}^{2}=86.6$ (77.8\% to 91.9\%) (Figure 3). Funnel plots displayed an asymmetrical pattern for in-hospital mortality but not for 30 -day mortality studies. The results of the sensitivity analysis suggest that three studies contribute to residual heterogeneity; removing them from the meta-analysis would reduce variability between studies. However, because this did not affect the results, these studies were retained. Meta-regression revealed that study quality (Down and Black score) $(P=0.003)$, inclusion of a definition of appropriate antibiotic usage $(P=0.0194)$, and studies reporting outcome for sepsis $(P=0.0001)$ significantly influenced the meta-analysis on in-hospital mortality.

The studies on 28-day [34,55] and 60-day [51] mortality reported significantly higher mortality ratios in patients receiving IAAT: respectively $P=0.007$ [34], $P=0.001$ [55], and $P=0.023$ [51]. The one study [8] that measures the mortality rate at 12 weeks did not reveal a significant difference (Table 4). 
Table 2 Definition and incidence of (in)appropriate antibiotic therapy in the reviewed studies

\begin{tabular}{|c|c|c|c|c|c|c|c|c|c|c|c|}
\hline \multirow[t]{3}{*}{ Reference } & \multicolumn{11}{|c|}{ Appropriate empiric antibiotic therapy } \\
\hline & \multicolumn{11}{|c|}{ Aspects of appropriate antibiotic therapy } \\
\hline & Definition & $\begin{array}{l}\text { According to } \\
\text { the culture }\end{array}$ & Timing & Dose & $\begin{array}{l}\text { According to } \\
\text { guidelines }\end{array}$ & Route & Indication & Duration & $\begin{array}{l}\text { No known } \\
\text { contraindication }\end{array}$ & Frequency & $\begin{array}{l}\text { Number } \\
\text { of items }\end{array}$ \\
\hline Kim et al. [21] & $\mathrm{Y}$ & Y & $\bar{Y}$ & $\mathrm{~N}$ & $N$ & Y & $\mathrm{N}$ & $\mathrm{N}$ & $\mathrm{N}$ & $\mathrm{N}$ & 3 \\
\hline Kang et al. [12] $]^{a}$ & $\mathbf{N}$ & & & & & & & & & & \\
\hline Micek et al. [33] ${ }^{a}$ & $\mathbf{N}$ & & & & & & & & & & \\
\hline Luna et al. [34] & $\mathrm{Y}$ & Y & $\mathrm{N}$ & $\mathrm{N}$ & Y & $\mathrm{N}$ & N & $\mathrm{N}$ & $\mathrm{N}$ & $\mathrm{N}$ & 2 \\
\hline Kim et al. [8] & $\mathrm{Y}$ & Y & Y & N & N & Y & N & $\mathrm{N}$ & N & $\mathrm{N}$ & 3 \\
\hline Scarsi et al. [22] ${ }^{a}$ & $\mathrm{Y}$ & Y & Y & Y & Y & N & N & N & N & N & 4 \\
\hline Marschall et al. [36] ${ }^{a}$ & $\mathrm{Y}$ & Y & Y & N & N & N & N & $\mathrm{N}$ & N & $\mathrm{N}$ & 2 \\
\hline Shorr et al. [37] ${ }^{a}$ & $\mathrm{Y}$ & Y & Y & N & N & N & N & N & N & N & 2 \\
\hline Rodriguez-Bano et al. [38] & $Y$ & Y & Y & Y & N & Y & N & N & N & N & 4 \\
\hline Ammerlaan et al. [39] ${ }^{a}$ & $\mathrm{Y}$ & Y & Y & N & N & Y & N & $\mathrm{N}$ & N & $\mathrm{N}$ & 3 \\
\hline Erbay et al. [19] ${ }^{a}$ & $\mathrm{Y}$ & Y & Y & Y & Y & Y & N & N & N & N & 5 \\
\hline Kumar et al. [40] ${ }^{a}$ & $Y$ & Y & Y & N & N & N & N & N & N & N & 2 \\
\hline Tseng et al. [41] ${ }^{a}$ & $Y$ & Y & $\mathrm{N}$ & N & N & N & Y & $\mathrm{N}$ & $\mathrm{N}$ & N & 2 \\
\hline Micek et al. [42] ${ }^{a}$ & $Y$ & Y & Y & N & N & N & Y & Y & N & N & 4 \\
\hline Paul et al. [43] ${ }^{a}$ & $\mathrm{Y}$ & Y & Y & N & N & N & N & $\mathrm{N}$ & N & N & 2 \\
\hline Joung et al. [44] ${ }^{a}$ & $Y$ & Y & Y & Y & N & Y & N & N & N & N & 4 \\
\hline Shorr et al. [45] & $\mathbf{N}$ & & & & & & & & & & \\
\hline Suppli et al. [46] ${ }^{a}$ & $Y$ & Y & Y & Y & Y & N & Y & Y & Y & N & 7 \\
\hline Reisfeld et al. [47] ${ }^{a}$ & $Y$ & Y & N & Y & N & N & N & $\mathrm{N}$ & N & Y & 3 \\
\hline Wilke et al. [48] & $\mathrm{Y}$ & $\mathrm{N}$ & $\mathrm{N}$ & N & Y & N & N & $\mathrm{N}$ & $\mathrm{N}$ & $\mathrm{N}$ & 1 \\
\hline Lye et al. [50] & $\mathrm{Y}$ & Y & $\mathrm{N}$ & Y & Y & N & N & $\mathrm{N}$ & $\mathrm{N}$ & N & 3 \\
\hline Tseng et al. [51] & $Y$ & N & N & N & N & N & Y & $\mathrm{N}$ & N & N & 1 \\
\hline Chen et al. [52] & $Y$ & Y & Y & $\mathrm{N}$ & N & $\mathrm{N}$ & N & $\mathrm{N}$ & $\mathrm{N}$ & $\mathrm{N}$ & 2 \\
\hline Labelle et al. [54] ${ }^{a}$ & $Y$ & Y & Y & N & N & N & N & N & N & N & 2 \\
\hline Chen et al. [55] & $\mathrm{Y}$ & Y & Y & Y & Y & Y & N & $\mathrm{N}$ & $\mathrm{N}$ & N & 5 \\
\hline Frakking et al. [56] ${ }^{a}$ & $\mathrm{Y}$ & Y & Y & N & N & N & N & Y & N & N & 3 \\
\hline Tumbarello et al. [57] ${ }^{a}$ & $\mathrm{~N}$ & & & & & & & & & & \\
\hline Total & 23 & 21 & 17 & 8 & 7 & 7 & 4 & 3 & 1 & 1 & \\
\hline
\end{tabular}


Table 2 Definition and incidence of (in)appropriate antibiotic therapy in the reviewed studies (Continued)

\begin{tabular}{|c|c|c|c|c|c|c|c|c|}
\hline \multirow[t]{3}{*}{ Reference } & \multicolumn{8}{|c|}{ Inappropriate empiric antibiotic therapy } \\
\hline & \multicolumn{8}{|c|}{ Aspects of inappropriate antibiotic therapy } \\
\hline & Definition & $\begin{array}{l}\text { Intermediate or full } \\
\text { in vitro resistance }\end{array}$ & Timing & Omission & Indication & Route & $\begin{array}{l}\text { Number } \\
\text { of items }\end{array}$ & $\%$ IAAT \\
\hline Kim et al. [21] ${ }^{a}$ & $\mathbf{N}$ & & & & & & & 76.38 \\
\hline Kang et al. [12] $]^{a}$ & $\mathbf{Y}$ & Y & Y & Y & N & N & 3 & 52.80 \\
\hline Micek et al. [33] ${ }^{a}$ & $\mathrm{Y}$ & Y & $\mathrm{N}$ & Y & $\mathrm{N}$ & $\mathrm{N}$ & 2 & 24.59 \\
\hline Luna et al. [34] & $\mathrm{Y}$ & Y & Y & $\mathrm{N}$ & $\mathrm{N}$ & N & 2 & 68.42 \\
\hline Kim et al. [8] & $\mathrm{N}$ & & & & & & & 49.16 \\
\hline Scarsi et al. [22] & $\mathrm{Y}$ & Y & Y & N & N & N & 2 & 14.14 \\
\hline Marschall et al. [36] & $Y$ & Y & N & Y & N & N & 2 & 31.6 \\
\hline Shorr et al. [37] $]^{a}$ & $\mathrm{~N}$ & & & & & & & 76.98 \\
\hline Rodriguez-Bano et al. [38] & $\mathbf{N}$ & & & & & & & 78.95 \\
\hline Ammerlaan et al. [39] ${ }^{a}$ & $Y$ & Y & Y & Y & Y & Y & 5 & 28.14 \\
\hline Erbay et al. [19] $]^{a}$ & $\mathbf{N}$ & & & & & & & 58.25 \\
\hline Kumar et al. [40] ${ }^{\mathrm{a}}$ & $Y$ & Y & Y & N & N & N & 2 & 19.88 \\
\hline Tseng et al. [41] $]^{a}$ & $\mathrm{Y}$ & Y & N & N & Y & N & 2 & 49.26 \\
\hline Micek et al. [42] ${ }^{a}$ & $\mathbf{N}$ & & & & & & & 31.32 \\
\hline Paul et al. [43] ${ }^{a}$ & $\mathrm{~N}$ & & & & & & & 67.06 \\
\hline Joung et al. [44] ${ }^{a}$ & $\mathrm{Y}$ & Y & Y & N & N & N & 2 & 57.76 \\
\hline Shorr et al. [45] & $\mathrm{Y}$ & Y & Y & Y & N & N & 3 & 31.30 \\
\hline Suppli et al. [46] ${ }^{a}$ & $\mathrm{~N}$ & & & & & & & 25.51 \\
\hline Reisfeld et al. [47] ${ }^{a}$ & $\mathrm{~N}$ & & & & & & & 39.95 \\
\hline Wilke et al. [48] ${ }^{a}$ & $\mathrm{~N}$ & & & & & & & 51.58 \\
\hline Lye et al. [50] ${ }^{a}$ & $\mathrm{~N}$ & & & & & & & 43.56 \\
\hline Tseng et al. [51] & $\mathbf{N}$ & & & & & & & 56.44 \\
\hline Chen et al. [52] & $\mathbf{N}$ & & & & & & & 38.98 \\
\hline Labelle et al. [54] ${ }^{\mathrm{a}}$ & $\mathrm{N}$ & & & & & & & 51.88 \\
\hline Chen et al. [55] & $\mathrm{N}$ & & & & & & & 27.21 \\
\hline Frakking et al. [56] ${ }^{\mathrm{a}}$ & $\mathrm{N}$ & & & & & & & 63.36 \\
\hline Tumbarello et al. [57] ${ }^{a}$ & $\mathrm{Y}$ & Y & N & $\mathrm{N}$ & $\mathrm{N}$ & N & 1 & 50.91 \\
\hline Total & 11 & 11 & 7 & 5 & 2 & 1 & & \\
\hline
\end{tabular}

Included in the meta-analysis. IAAT, inappropriate antibiotic therapy; $\mathrm{N}, \mathrm{no} ; \mathrm{Y}$, yes. 
Table 3 Summary of mortality data included in the meta-analysis

\begin{tabular}{|c|c|c|c|c|}
\hline Reference & Time of mortality assessment & AAT mortality rate, $\%$ & IAAT mortality rate, $\%$ & $P$ value \\
\hline Kim et al. [21] & 30 & 36.67 & 41.24 & 0.36 \\
\hline Kang et al. [12] & 30 & 27.41 & 38.41 & 0.049 \\
\hline Micek et al. [33] & $\mathrm{IHM}$ & 17.83 & 30.67 & 0.018 \\
\hline Scarsi et al. [22] & $\| \mathrm{HM}$ & 16.07 & 13.60 & 0.48 \\
\hline Marschall et al. [36] & $\mathrm{HM}$ & 14.03 & 13.92 & 1.0 \\
\hline Shorr et al. [37] & $\mathrm{HM}$ & 11.94 & 19.64 & 0.15 \\
\hline Rodríguez-Baño et al. [38] & 30 & 18.18 & 24.24 & 0.3 \\
\hline Ammerlaan et al. [39] & 30 & 25.00 & 21.27 & NS \\
\hline Erbay et al. [19] & 30 & 39.53 & 65.00 & 0.011 \\
\hline Kumar et al. [40] & $\mathrm{IHM}$ & 48.00 & 89.70 & $<0.0001$ \\
\hline Tseng et al. [41] & $\mathrm{HM}$ & 35.44 & 50.00 & OR $2.17(1.4-3.38) 0.001$ \\
\hline Micek et al. [42] & $\mathrm{HM}$ & 36.40 & 51.68 & $<0.001$ \\
\hline Paul et al. [43] & 30 & 33.33 & 49.12 & 0.001 \\
\hline Joung et al. [44] & 30 & 22.45 & 49.25 & $<0.0001$ \\
\hline Suppli et al. [46] & 30 & 20.55 & 40.00 & 0.009 \\
\hline Reisfeld et al. [47] & 30 & 33.48 & 46.36 & OR 1.4 (0.86-2.29) (NS) \\
\hline Wilke et al. [48] & $\| \mathrm{HM}$ & 14.02 & 26.32 & 0.021 \\
\hline Lye et al. [50] & $\mathrm{HM}$ & 19.16 & 26.19 & OR $0.67(0.46-0.96) 0.03$ \\
\hline Labelle et al. [54] & $\mathrm{HM}$ & 51.38 & 68.30 & $<0.001$ \\
\hline Frakking et al. [56] & 30 & 18.82 & 20.41 & NS \\
\hline Tumbarello et al. [57] & $\mathrm{IHM}$ & 24.07 & 64.29 & $<0.001$ \\
\hline
\end{tabular}

AAT, appropriate antibiotic therapy; IAAT, inappropriate antibiotic therapy; IHM, in-hospital mortality; OR, odds ratio; NS, not significant.

\section{LOS and costs}

Four studies reported the effect on LOS: total LOS $[48,55]$ or LOS after the onset of infection $[36,45]$. In one of the two studies [45], the mean LOS after infection onset was significantly $(P=0.022)$ higher in the group sepsis patients with IAAT. This indicates that IAAT independently increased the median attributable LOS by 2 days. However, the study by Marschall et al. [36] found no significant differences in LOS post-onset $(P=0.09)$ in patients with Gram-negative bacteraemia. Appropriately treated patients with ventilator-associated pneumonia had a significantly shorter total LOS $(P=0.022)$ [48]. Nevertheless, Chen et al. [55] found no differences in the total LOS of patients with community-onset bloodstream infections.

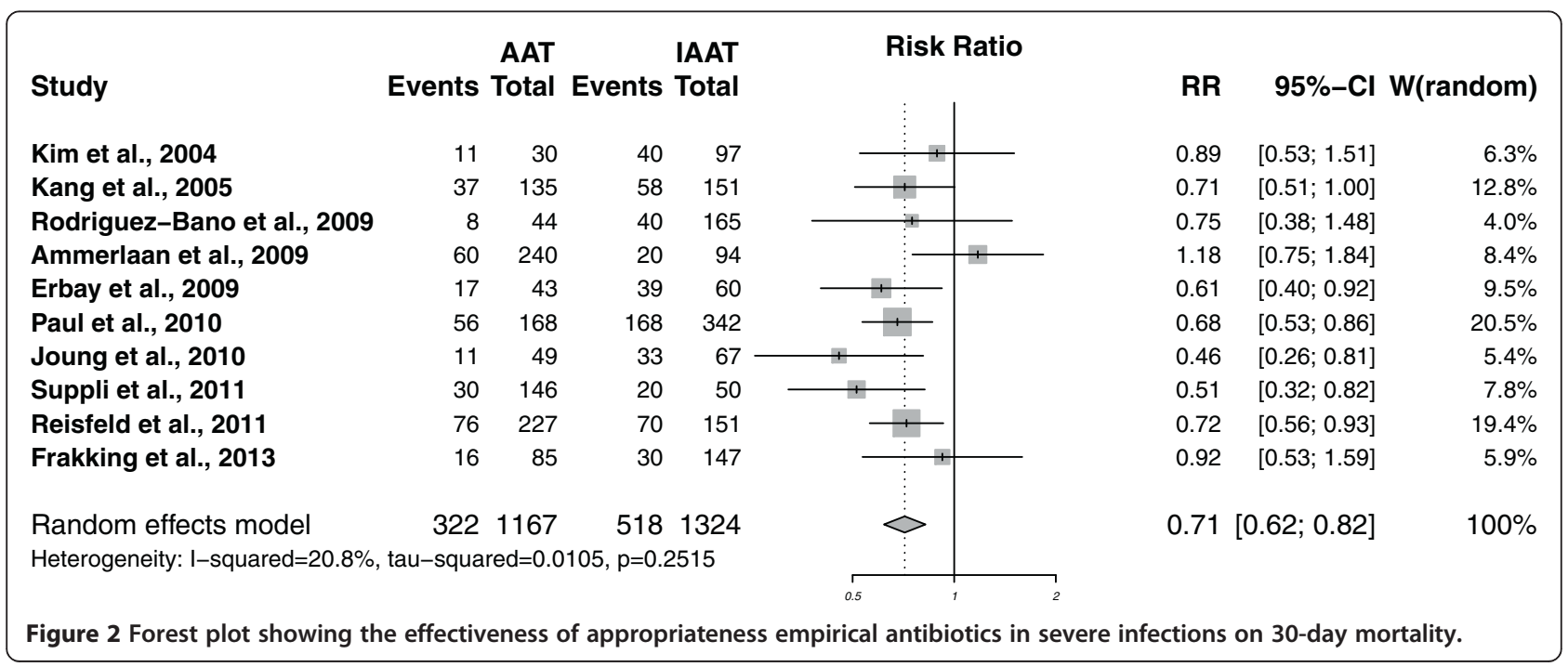




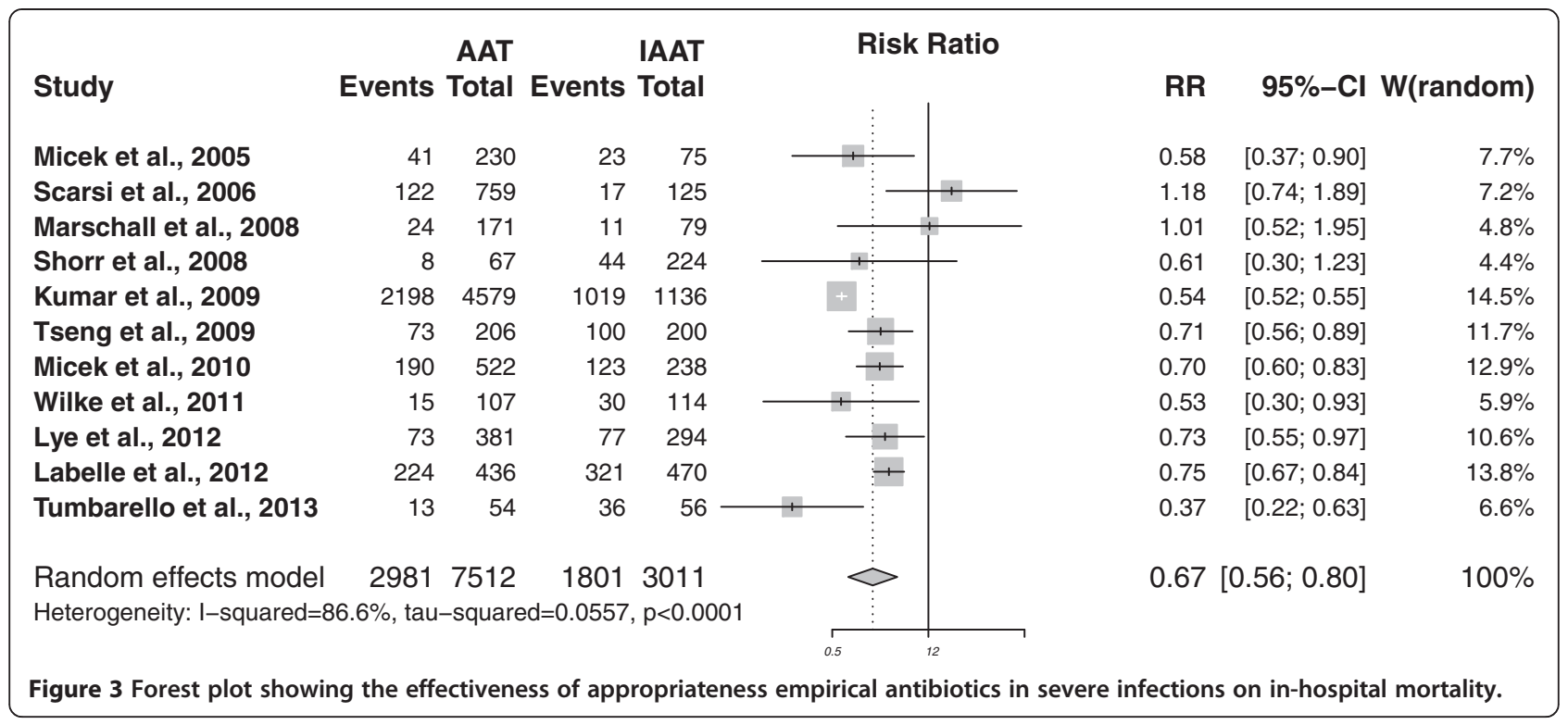

The costs were assessed in only two studies $[37,48]$. The total costs for patients with IAAT were significantly higher in both studies $(P \leq 0.01)$.

\section{Discussion}

The incidence of patients with severe infections is substantial. Previous studies confirmed-as proven by the low number needed to treat-that correct antibiotic treatment is a crucial determinant of therapeutic success [66]. Therefore, a systematic review with meta-analysis was conducted to investigate the incidence and consequences of IAAT on the outcome in hospitalized patients with infection.

Definitions and criteria items used to denote (I)AAT varied substantially between studies. However, most definitions included the criterion 'matching with the in vitro susceptibility' or 'intermediate or full in vitro resistance'. The timing of administration of the antibiotics was taken into account in only $71 \%$ of the definitions. Timing of admission is, however, an important aspect of adequate antibiotic therapy. In patients with septic shock, each hour of delay in antimicrobial therapy is associated with an average decrease in survival of 7.6\% [13]. Rivers et al. [67] showed that early goal-directed therapy provides significant benefits with respect to outcome in patients with severe sepsis and septic shock. For patients with Staphylococcus aureus bacteraemia, the breakpoint between delayed and early treatment was 44.75 hours, and delayed treatment was found to be an independent predictor of infection-related mortality [68]. Based on this heterogeneity in the definitions, it was impossible to estimate the overall incidence of IAAT. However, IAAT ranged from $14.1 \%$ to $78.9 \%$, and $46.4 \%$ of studies described an incidence of IAAT of $50 \%$ or more. Given this high incidence, health-care professionals must become aware of this problem. Moreover, in an era of rising antimicrobial resistance rates, choosing empiric AAT is an increasing challenge. The meta-analysis, involving 13,014 patients, suggests that the empiric AAT reduces 30-day mortality (RR $0.71,95 \%$ CI 0.62 to 0.82 ) and in-hospital mortality (RR $0.67,95 \%$ CI 0.56 to 0.80 ). In addition, empiric AAT positively affects LOS and costs.

Strengths of this study include the comprehensive search strategy, the methodological quality assessment, and the random-effects model analysis combined with meta-regression. Besides the methodological strengths, the study has limitations. First, the present findings should be interpreted in the context of the included

Table 4 Overview of studies evaluating the mortality rate at 28 and 60 days and 12 weeks

\begin{tabular}{llll}
\hline Reference & Time of mortality assessment & AAT mortality rate & IAAT mortality rate \\
\hline Luna et al., 2006 [34] & 28 days & 29.17 & 63.46 \\
Chen et al., 2013 [55] & 28 days & 9.09 & 38.04 \\
Tseng et al., 2012 [51] & 60 days & 28.17 & 55.43 \\
Kim et al., 2006 [8] & 12 weeks & 28.10 & 38.46 \\
\hline
\end{tabular}

AAT, appropriate antibiotic therapy; IAAT, inappropriate antibiotic therapy; NS, not significant. 
studies and their limitations: the heterogeneity in patients' characteristics, definitions of IAAT, and the time span of outcome assessment. Second, the lack of RCTs is this review could be seen as a major limitation. The lack of RCTs regarding this topic stems from obvious ethical constraints. Given the methodological heterogeneity of the included (retro- and prospective) observational studies, an overall meta-analysis was impossible. Meta-analysis was performed for 30-day and in-hospital mortality only. Third, several potential biasing and confounding elements might have hampered this metaanalysis. The reported diseases and the diagnosis process, the study quality quantified by the Downs and Black instrument, the quality of the health-care systems in the different countries, and the definitions of adequate antibiotic therapy had a marked influence on the metaanalysis of in-hospital mortality. Nevertheless, we aggregated all reported diseases to avoid a small numbers problem. Probably the cleanest data for assessing the impact of (I)AAT would be for bacteremia, as this is the infection that can most accurately be defined. Fourth, this analysis does not cover all areas, such as fungemiae. However, this limitation creates opportunities for further research. Fifthly, we used the (criteria of the) definitions used in the included studies. Most of the studies approached the definition one-sided and used only the criteria 'matching with the culture' and 'according to the guidelines'. However, appropriateness of antibiotic treatment is related not only to the substance itself but also to dosing or administration route (or both) of the antibiotic. Finally, during this review, we focused on (in)appropriate antibiotic therapy. Off course, inappropriate therapy is not only determined by the antibiotic used. Further research could focus on other aspects of (in)appropriate therapy.

\section{Conclusions}

This systematic review demonstrates a very high incidence of IAAT in patients with severe bacterial infection, such as BSI, pneumonia, sepsis, or septic shock. Accurate empirical treatment of these severe infections is not a simple process seen in currently reported rates of IAAT. Meta-analysis provides evidence that empiric inappropriate use of empiric antibiotics increases 30-day and in-hospital mortality in these patients. Clinicians should be aware of this problem, and further improvement actions should be taken. Inappropriate antibiotic treatment stems from several causes, mainly due to resistance; therefore, it is not easy to find the most appropriate treatment option. As long as general recommendations about antibiotic stewardship are missing, problems will remain. Computerized decision support, including complex and locally calibrated decision algorithms $[69,70]$ or early molecular identification or both, might be helpful.

\section{Key messages}

- The definitions of IAAT varied. Nevertheless, almost every definition included the element 'matching with the in vitro susceptibility' or 'intermediate or full in vitro resistance'.

- This systematic review demonstrates a very high incidence of empiric IAAT in patients with severe infection, such as BSI, pneumonia, sepsis, or septic shock.

- Meta-analysis provides evidence that empiric IAAT increases 30-day and in-hospital mortality in patients with a severe infection.

- Clinicians should be aware of this problem, and further improvement actions should be taken. Further computerized decision support needs to be developed.

\section{Additional file}

Additional file 1: Appendix 1. Literature search strategy. MeSH, Medical Subject Headings. Appendix 2. Description of exclusion criteria. Appendix 3. Downs and Black checklist for methodological quality assessment of included studies. Appendix 4. Data collection tool. Appendix 5. Reference of studies included in systematic review but not in the meta-analysis.

\section{Abbreviations}

AAT: appropriate antibiotic therapy; BSI: bloodstream infection; Cl: confidence interval; d.f.: degrees of freedom; IAAT: inappropriate antibiotic therapy; LOS: length of stay; RCT: randomized controlled trial; RR: risk ratio.

\section{Competing interests}

The authors declare that they have no competing interests.

\section{Authors' contributions}

KM conceived and designed the study; carried out the literature searches; selected the studies; assessed the included studies; analyzed, interpreted, and synthesized the data; contributed to the statistical analysis; and wrote the manuscript. AL carried out the literature searches, selected the studies, and assessed the included studies. JB performed the statistical analysis, contributed to data interpretation, and revised the statistical portions of the report. NC and AV made substantial contributions to the design, acted as the third reviewer during the study appraisal and the data extraction in case of disagreement, and critically revised the manuscript for important intellectual content. All authors approved the final version to be published and agree to be accountable for all aspects of the work.

\section{Acknowledgements}

This study is supported by 'Limburg Sterk Merk' (LSM), Universiteitslaan 1, 3500 Hasselt, Belgium. LSM is a foundation of public utility that supports health-care and economic development projects. Nele Geurden is acknowledged for her linguistic advice.

\section{Author details}

${ }^{1}$ Hasselt University, Faculty of Medicine and Life Sciences, Agoralaan, Building D, Room C53, Diepenbeek BE3590, Belgium. ${ }^{2}$ Jessa Hospital, Stadsomvaart 11, Hasselt BE3500, Belgium. ${ }^{3}$ Hasselt University, Faculty of Business Economics, Agoralaan, Building D, Diepenbeek BE3590, Belgium. ${ }^{4}$ KU Leuven, Centre for Health Services and Nursing Research, Kapucijnenvoer 35/3, Leuven BE3000, Belgium. ${ }^{5}$ Antwerp Management School, Health Care Management, Sint-Jacobsmarkt 9, Antwerp BE2000, Belgium. 
Received: 14 November 2014 Accepted: 9 February 2015

Published online: 16 February 2015

\section{References}

1. World Health Organization. World health statistics 2012. http://www.who. int/gho/publications/world_health_statistics/EN_WHS2012_Full.pdf. Accessed March 9, 2015

2. Heron M, Hoyert S, Murphy J, Kochanek K, Tejada-Vera B. Deaths: final data for 2006. Division of Vital Statistics, Centers for Disease Control and Prevention. Natl Vital Stat Rep. 2009;57:1-136.

3. Wenzel RP, Edmond MB. The impact of hospital-acquired bloodstream infections. Emerg Infect Dis. 2001;7:174-7.

4. Dellinger RP. Cardiovascular management of septic shock. Crit Care Med. 2003;31:946-55.

5. Eagye KJ, Kim A, Laohavaleeson S, Kuti UL, Nicolau DP. Surgical site infections: does inadequate antibiotic therapy affect patient outcomes? Surg Infect (Larchmt). 2009;10:323-31.

6. Fraser A, Paul M, Almanasreh N, Tacconelli E, Frank U, Leibovici L. Benefit of appropriate empirical antibiotic treatment: thirty-day mortality and duration of hospital stay. Am J Med. 2006;119:970-6.

7. Fowler RA, Flavin KE, Barr J, Weinacker A, Parsonnet J, Gould M. Variability in antibiotic prescribing patterns and outcomes in patients with clinically suspected ventilator- associated pneumonia. Chest. 2003;123:835-44.

8. Kim S-H, Park W-B, Lee C-S, Kang C-I, Bang J-W, Kim H-B, et al. Outcome of inappropriate empirical antibiotic therapy in patients with Staphylococcus aureus bacteraemia: analytical strategy using propensity scores. Clin Microbiol Infect. 2006;12:13-21.

9. Schweizer ML, Furuno JP, Harris AD, Johnson JK, Shardell MD, McGregor JC, et al. Empiric antibiotic therapy for Staphylococcus aureus bacteremia may not reduce in-hospital mortality: a retrospective cohort study. PLoS One. 2010;5:e11432-8

10. Thom KA, Schweizer ML, Osih RB, McGregor JC, Furuno JP, Perencevich EN, et al. Impact of empiric antimicrobial therapy on outcomes in patients with Escherichia coli and Klebsiella pneumoniae bacteremia: a cohort study. BMC Infect Dis. 2008:8:116-24

11. Osih RB, McGregor JC, Rich SE, Moore AC, Furuno JP, Perencevich EN, et al. Impact of empiric antibiotic therapy on outcomes in patients with Pseudomonas aeruginosa bacteremia. Antimicrob Agents Chemother. 2007;51:839-44.

12. Kang C, Kim S, Park WB, Lee K, Kim H, Kim E, et al. Bloodstream infections caused by antibiotic-resistant Gram-negative bacilli: risk factors for mortality and impact of inappropriate initial antimicrobial therapy on outcome. Antimicrob Agents Chemother. 2005;49:760-6.

13. Kumar A, Roberts D, Wood KE, Light B, Parrillo JE, Sharma S, et al. Duration of hypotension before initiation of effective antimicrobial therapy is the critical determinant of survival in human septic shock. Crit Care Med. 2006;34:1589-96.

14. Ibrahim EH, Sherman G, Ward S, Fraser VJ, Kollef MH. The influence of inadequate antimicrobial treatment of bloodstream infections on patient outcomes in the ICU setting. Chest. 2000;118:146-55.

15. Labelle A, Micek S, Roubinian N, Kollef M. Treatment-related risk factors for hospital mortality in Candida bloodstream infections. Crit Care Med. 2008;36:2967-72

16. Schramm G, Johnson J, Doherty J, Micek S, Kollef M. Methicillin-resistant Staphylococcus aureus sterile-site infection: the importance of appropriate initial antimicrobial treatment. Crit Care Med. 2006;34:2069-74.

17. Romero-Vivas J, Rubio M, Fernandez C, Picazo J. Mortality associated with nosocomial bacteremia due to methicillin-resistant Staphylococcus aureus. Clin Infect Dis. 1995;21:1417-23.

18. Leibovici L, Shraga I, Drucker M, Konigsberger H, Samra Z, Pitlik SD. The benefit of appropriate empirical antibiotic treatment in patients with bloodstream infection. J Intern Med. 1998;244:379-86.

19. Erbay A, Idil A, Gözel MG, Mumcuoğlu I, Balaban N. Impact of early appropriate antimicrobial therapy on survival in Acinetobacter baumannii bloodstream infections. Int J Antimicrob Agents. 2009;34:575-9.

20. Lin MY, Weinstein RA, Hota B. Delay of active antimicrobial therapy and mortality among patients with bacteremia: impact of severe neutropenia. Antimicrob Agents Chemother. 2008;52:3188-94.

21. Kim S, Park W, Lee K, Kang C, Bang J, Kim H, et al. Outcome of inappropriate initial antimicrobial treatment in patients with methicillin-resistant Staphylococcus aureus bacteraemia. J Antimicriobial Chemother. 2004;54:489-97.
22. Scarsi KK, Feinglass JM, Scheetz MH, Postelnick MJ, Bolon MK, Noskin GA. Impact of inactive empiric antimicrobial therapy on inpatient mortality and length of stay. Antimicrob Agents Chemother. 2006;50:3355-60.

23. Mcgregor JC, Rich SE, Harris AD, Perencevich EN, Osih R, Lodise TP, et al. A systematic review of the methods used to assess the association between appropriate antibiotic therapy and mortality in bacteremic patients. Clin Infect Dis. 2007;45:329-37.

24. Downs SH, Black N. The feasibility of creating a checklist for the assessment of the methodological quality both of randomised and non-randomised studies of health care interventions. J Epidemiol Community Health. 1998;52:377-84.

25. Deeks J, Dinnes J, D'Amico R, Sowden A, Sakarovitch C, Song F, et al. Evaluating non-randomised intervention studies. Health Technol Assess. 2003:7:iii-x. 1-173.

26. Saunders LD, Soomro GM, Buckingham J, Jamtvedt G, Raina P. Assessing the methodological quality of nonrandomized intervention studies. West J Nurs Res. 2003;25:223-37.

27. Chudyk AM, Jutai JW, Petrella RJ, Speechley M. Systematic review of hip fracture rehabilitation practices in the elderly. Arch Phys Med Rehabil. 2009;90:246-62.

28. Hooper P, Jutai JW, Strong G, Russell-Minda E. Age-related macular degeneration and low-vision rehabilitation: a systematic review. Can J Ophthalmol. 2008:43:180-7.

29. Samoocha D, Bruinvels DJ, Elbers NA, Anema JR, van der Beek AJ. Effectiveness of web-based interventions on patient empowerment: a systematic review and meta-analysis. J Med Internet Res. 2010;12:e23.

30. Team RDC. R: A Language and Environment for Statistical Computing. 2012th ed. Vienna: R Foundation for Statistical Computing; 2012

31. DerSimonian R, Laird N. Meta-analysis in clinical trials. Control Clin Trials. 1986;7:177-88.

32. Mueller EW, Hanes SD, Croce MA, Wood GC, Boucher BA, Fabian TC. Effect from multiple episodes of inadequate empiric antibiotic therapy for ventilator-associated pneumonia on morbidity and mortality among critically ill trauma patients. J Trauma Inj Infect Crit Care. 2005;58:94-101.

33. Micek ST, Lloyd AE, Ritchie DJ, Reichley RM, Fraser VJ, Kollef MH. Pseudomonas aeruginosa bloodstream infection: importance of appropriate initial antimicrobial treatment. Antimicrob Agents Chemother. 2005;49:1306-11.

34. Luna CM, Aruj P, Niederman MS, Garzon J, Violi D, Prignoni A, et al. Appropriateness and delay to initiate therapy in ventilator-associated pneumonia'. Eur Respir. 2006;27:158-64.

35. Fujita T, Ishida Y, Yanaga K. Impact of appropriateness of initial antibiotic therapy on outcome of postoperative pneumonia. Langenbecks Arch Surg. 2008;393:487-91.

36. Marschall J, Agniel D, Fraser VJ, Doherty J, Warren DK. Gram-negative bacteraemia in non-ICU patients: factors associated with inadequate antibiotic therapy and impact on outcomes. J Antimicriobial Chemother. 2008;61:1376-83.

37. Shorr AF, Micek ST, Pharm D, Kollef MH. Inappropriate therapy for methicillin-resistant Staphylococcus aureus: resource utilization and cost implications. Crit Care Med. 2008;36:2335-40.

38. Rodríguez-Baño J, Millán AB, Domínguez MA, Borraz C, González MP Almirante $B$, et al. Impact of inappropriate empirical therapy for sepsis due to health care-associated methicillin-resistant Staphylococcus aureus. J Infect. 2009;58:131-7.

39. Ammerlaan H, Seifert H, Harbarth S, Brun-Buisson C, Torres A, Antonelli M, et al. Adequacy of antimicrobial treatment and outcome of Staphylococcus aureus bacteremia in 9 Western European countries. Clin Infect Dis. 2009;49:997-1005.

40. Kumar A, Ellis P, Arabi Y, Roberts D, Light B, Parillo J, et al. Initiation of inappropriate antimicrobial therapy results in a fivefold reduction of survival in human septic shock. Chest. 2009;136:1237-48.

41. Tseng C-C, Fang W-F, Huang K-T, Chang P-W, Tu M-L, Shiang Y-P, et al. Risk factors for mortality in patients with nosocomial Stenotrophomonas maltophilia pneumonia. Infect Control Hosp Epidemiol. 2009;30:1193-202.

42. Micek ST, Welch EC, Khan J, Pervez M, Doherty JA, Reichley RM, et al. Empiric combination antibiotic therapy is associated with improved outcome against sepsis due to Gram-negative bacteria: a retrospective analysis. Antimicrob Agents Chemother. 2010;54:1742-8.

43. Paul M, Kariv G, Goldberg E, Raskin M, Shaked H, Hazzan R, et al. Importance of appropriate empirical antibiotic therapy for methicillin-resistant Staphylococcus aureus bacteraemia. J Antimicrob Chemother. 2010;65:2658-65. 
44. Joung M, Kwon K, Kang C, Cheong H, Rhee J, Jung D, et al. Impact of inappropriate antimicrobial therapy on outcome in patients with hospital-acquired pneumonia caused by Acinetobacter baumannii. J Infect. 2010;61:212-8

45. Shorr AF, Micek ST, Welch EC, Doherty JA, Reichley RM, Kollef MH. Inappropriate antibiotic therapy in Gram-negative sepsis increases hospital length of stay. Crit Care Med. 2011;39:46-51.

46. Suppli M, Aabenhus R, Harboe ZB, Andersen LP, Tvede M, Jensen J-US. Mortality in enterococcal bloodstream infections increases with inappropriate antimicrobial therapy. Clin Microbiol Infect. 2011;17:1078-83.

47. Reisfeld S, Paul M, Gottesman BS, Shitrit P, Leibovici L, Chowers M. The effect of empiric antibiotic therapy on mortality in debilitated patients with dementia. Eur J Clin Microbiol Infect Dis. 2011;30:813-8.

48. Wilke MH, Grube R, Bodmann KF. Guideline - adherent initial intravenous antibiotic therapy for hospital-acquired, ventilator-associated pneumonia is clinically superior, saves lives and is cheaper than non-guideline-adherent therapy. Eur J Med Res. 2011;16:315-23.

49. De Rosa FG, Pagani N, Fossati L, Raviolo S, Cometto C, Cavallerio P, et al. The effect of inappropriate therapy on bacteremia by ESBL-producing bacteria. Infection. 2011;39:555-61.

50. Lye DC, Earnest A, Ling ML, Lee T, Yong H, Fisher DA, et al. The impact of multidrug resistance in healthcare-associated and nosocomial Gramnegative bacteraemia on mortality and length of stay: cohort study. Clin Microbiol Infect. 2012;18:502-8.

51. Tseng C-C, Liu S-F, Wang C-C, Tu M-L, Chung Y-H, Lin M-C, et al. Impact of clinical severity index, infective pathogens, and initial empiric antibiotic use on hospital mortality in patients with ventilator-associated pneumonia. Am J Infect Control. 2012;40:648-52. Elsevier Inc.

52. Chen R, Yan Z, Feng D, Luo Y, Wang L, Shen D. Nosocomial bloodstream infection in patients caused by factors for hospital mortality. Chin Med J. 2012;125:226-9.

53. Kim YJ, Kim II S, Hong K, Kim YR, Park YJ, Kang M. Risk factors for mortality in patients with Carbapenem-resistant Acinetobacter baumannii bacteremia: impact of appropriate antimicrobial therapy. J Korean Med Sci. 2012;27:471-5.

54. Labelle A, Juang P, Reichley R, Micek S, Hoffmann J, Hoban A, et al. The determinants of hospital mortality among patients with septic shock receiving appropriate initial antibiotic treatment. Crit Care Med. 2012:40:2016-21

55. Chen H-C, Lin W-L, Lin C-C, Hsieh W-H, Hsieh C-H, Wu M-H, et al. Outcome of inadequate empirical antibiotic therapy in emergency department patients with community-onset bloodstream infections. J Antimicrob Chemother. 2013;68:947-53.

56. Frakking FNJ, Rottier WC, Dorigo-Zetsma JW, van Hattem JM, van Hees BC, Kluytmans JAJW, et al. Appropriateness of empirical treatment and outcome in bacteremia caused by extended-spectrum- $\beta$-lactamase-producing bacteria. Antimicrob Agents Chemother. 2013;57:3092-9.

57. Tumbarello M, De Pascale G, Trecarichi EM, Spanu T, Antonicelli F, Maviglia $R$, et al. Clinical outcomes of Pseudomonas aeruginosa pneumonia in intensive care unit patients. Intensive Care Med. 2013;39:682-92

58. Ortega M, Marco F, Soriano A, Almela M, Martínez JA, Pitart C, et al. Epidemiology and prognostic determinants of bacteraemic catheteracquired urinary tract infection in a single institution from 1991 to 2010. J Infect. 2013;67:282-7.

59. Knaus W, Draper E, Wagner D, Zimmerman J. APACHE II: a severity of disease classification system. Crit Care Med. 1985;13:818-29.

60. Charlson M, Pompei P, Ales KL, MacKenzie C. A new method of classifying prognostic comorbidity in longitudinal studies: development and validation. J Chronic Dis. 1987;40:373-83.

61. Vincent J-L, Moreno R, Takala J, Willatts S, De Mendonça A, Bruining H, et al. The SOFA (Sepsis-related Organ Failure Assessment) score to describe organ dysfunction/failure. Intensive Care Med. 1996;22:707-10.

62. Le Gall J-R, Lemeshow S, Saulnier F. New Simplified Acute Physiology Score (SAPS II) Based on a European/North American Multicenter Study. JAMA. 1993:270:2957-63.

63. Marshall JC, Cook DJ, Christou NV, Bernard GR, Sprung CL, Sibbald WJ. Multiple organ dysfunction score: a reliable descriptor of a complex clinical outcome. Crit Care Med. 1995;23:1638-52.

64. Paterson DL, Wen-Chien K, Von Gottberg A, Mohapatra S, Casellas JM, Goossens $\mathrm{H}$, et al. International prospective study of Klebsiella pneumoniae bacteremia: implications of extended-spectrum $\beta$-lactamase production in nosocomial infections. Ann Intern Med. 2004;140:26-32.
65. McCabe WR. Gram-negative JGG, Bacteremia I. Etiologie and Ecology. JAMA. 1962;110:847-55.

66. Paul M, Shani V, Muchtar E, Kariv G, Robenshtok E, Leibovici L, et al. Systematic review and meta-analysis of the efficacy of appropriate empiric antibiotic therapy for sepsis. Antimicrob Agents Chemother. 2010;54:4851-63.

67. Rivers E, Nguyen B, Havstad S, Ressler J, Muzzin A, Knoblich B, et al. Early goal-directed therapy in the treatment of severe sepsis and septic shock. N Engl J Med. 2001;345:1368-77.

68. Lodise TP, McKinnon PS, Swiderski L, Rybak MJ. Outcomes analysis of delayed antibiotic treatment for hospital-acquired Staphylococcus aureus bacteremia. Clin Infect Dis. 2003;36:1418-23.

69. Paul M, Andreassen S, Tacconelli E, Nielsen AD, Almanasreh N, Frank U, et al. Improving empirical antibiotic treatment using TREAT, a computerized decision support system: cluster randomized trial. J Antimicrob Chemother. 2006:58:1238-45.

70. Paul M, Nielsen AD, Goldberg E, Andreassen S, Tacconelli E, Almanasreh N, et al. Prediction of specific pathogens in patients with sepsis: evaluation of TREAT, a computerized decision support system. J Antimicrob Chemother. 2007;59:1204-7.

\section{Submit your next manuscript to BioMed Central and take full advantage of:}

- Convenient online submission

- Thorough peer review

- No space constraints or color figure charges

- Immediate publication on acceptance

- Inclusion in PubMed, CAS, Scopus and Google Scholar

- Research which is freely available for redistribution 